\title{
Performance Access of Critical Characteristics of stand alone Induction Generator
}

\author{
Tapas Kumar Mohapatra, Binod Sahu
}

\begin{abstract}
This paper presents the performance analysis of critical characteristics of standalone induction generators and proposes a novel method of evaluating the critical characteristics of SEIG under various operating condition. The minimum value of capacitance required for excitation and voltage build up in SEIG are also derived and embedded into the system. This paper deals with the study of various problems associated with induction motor (IM) when used as an induction generator and the experimental results which is obtained in the laboratory is compared with the Matlab results.
\end{abstract}

IndexTerms-Self excited induction generator (SEIG), Induction motor(IM), critical characteristics.

\section{INTRODUCTION}

In today's world of globalization, the increase of power consumption in several developing countries has led to the shifting of conventional energy sources towards renewable energy resources. Fossil fuels are an incredibly dense form of energy, and they took millions of years to become so. The rate at which the world consumes fossil fuels is much faster than its formation. Fossil fuels will therefore run out very soon. Since fossil fuels create a high level of air pollution which is threatening for human existence, different types of renewable energy resources such as wind energy, micro hydro and solar energy are employed [1], ,2]. Most of the developing countries holds abundance of renewable energy resources that can be employed for standalone application in places where power supply through grid is not feasible. Various types of renewable energy sources can be used as a prime mover in such remote areas. SEIG driven by microhydro turbine can be used to power such remote villages and hilly areas.[3] Synchronous generators are mostly used for power generation in large power plants but induction generators are being used more commonly over synchronous generators because of the following advantages such as less maintenance, high reliability, low cost, rugged construction, robust in nature, small size and ability to generate power at varying speed,[4]. Therefore SEIG is best suited and provides a good alternative to conventional synchronous generator for standalone application. In practice self excited induction generators are not easily available, so to design induction generator, an induction motor when runs at specific speed by some external means generates power and act as induction generator,[5]. Despite of supplying reactive power unlike synchronous generator, it absorbs reactive power from its excitation. Hence to provide reactive power,

\footnotetext{
Revised Manuscript Received on September 10, 2019.

Tapas Kumar Mohapatra, Dept. of Electrical Engineering, Siksha O Anusandhan Deemed to be University, Odisha, India.

(Email: tapasmohapatra@soa.ac.in)

Binod Sahu, Dept. of Electrical Engineering, Siksha O Anusandhan Deemed to be University, Odisha, India.

(Email: binodsahu@soa.ac.in)
}

the capacitor bank of specific rating must be connected across the stator of induction generator, such excited generator is known as self excited induction generator(SEIG). self excitation with suitable value of capacitor bank at stator terminals of induction machine demonstrate the principal operation of self-excited induction generator(SEIG)[4],[6].

\section{EXCITATION AND VOLTAGE BUILD UP IN SEIG}

By external means an excitation must be provided across the terminals of generator to build up voltage in SEIG. For this purpose the capacitors of proper rating must be connected across the generator terminal. The voltage will not build up if there is absence of proper value of residual magnetism, therefore it is require to have a suitable value of residual magnetism in the rotor of SEIG [7].

The concept of self excitation in induction machine is investigated by performing no load test in the laboratory. Also a specific range of capacitor bank required in excitation of SEIG is calculated. Initially when induction generator starts to run, a small voltage is build up by the effect of residual magnetism present in rotor. This small voltage is sufficient for capacitor current to flow which in turn increases the voltage until it is fully build up.[8]

\section{LOSS AND RESTORATION OF RESIDUAL MAGNETISM}

Beside many advantages, one main disadvantage of induction generator is loss of residual magnetism which may occur due to following reasons:-

- By the flow of excess amount of current.

- Due to short circuit.

- Too much increase of reactive load will consume reactive power from its excitation and cause voltage dip which destroy the residual magnetism of rotor.

If the residual magnetism of the machine gets destroyed by the reasons mentioned above, then it could be restored by the following methods:-

$\checkmark \quad$ Running the machine as a motor for 10 to 15 minutes.

$\checkmark \quad$ By charging the capacitor bank. when the capacitor bank is charged up to the rated machine voltage, the discharge current is sufficient to cause self excitation.

$\checkmark \quad$ If we increase the machine speed above rated value the residual magnetism will be restored. 
$\checkmark \quad$ When machine is at rest, connect 6 volt battery across the terminal of machine for 10 to 15 minutes and residual magnetism will be restored [9].

\section{THEORY OF SEIG}

Self-excited induction generator (SEIG) is very much suitable to produce electricity in isolated areas where extinction of grid is not economical. Generally, in hilly areas micro hydro turbine can be act as a prime mover to drive an induction generator and generates power at varying speed.[6] However induction motor is operated as induction generator, several difficulties can be faced during its operation. As an induction motor have very low residual magnetism, separate excitation is required in order to maintain particular amount of residual magnetism[10]. For providing self excitation, a capacitor bank of suitable rating must be connected across the terminal of machine. A capacitor bank provides sufficient amount of reactive power to the machine and maintain the residual magnetism and transfer some amount of reactive power required by reactive loads [7],[11].

During operation, an induction motor cannot behaves perfectly as induction generator because of its small hysteresis curve as compared to generator and therefore its residual magnetism can be lost easily. There are mainly two sides of possibilities that can lost the residual magnetism, first is from input side or supply side of machine and second is from load side of the machine. If the shaft speed of machine decreases below a particular value, then machine will shut down and there will be no residual magnetism left in the rotor (input or supply side). And if too much reactive load draws a large current from machine, then voltage will dip suddenly and destroy the residual magnetism (load side) [8].

\section{PERFORMANCE ANALYSIS OF SEIG}

The SEIG performance can be analysed by its equivalent circuitary. The per phase equivalent circuit of three phase SEIG is shown in Fig.1, where $R_{s}, R_{r}, R_{c}$ and $R_{L}$ are stator resistance,rotor resistance, core resistance and load resistance respectively. $\mathrm{X}_{\mathrm{s}}, \mathrm{X}_{\mathrm{r}}, \mathrm{X}_{\mathrm{m}}, \mathrm{X}_{\mathrm{c}}$ and $\mathrm{X}_{\mathrm{L}}$ describe stator reactance, rotor reactance, magnetizing reactance, excitation capacitor and load reactance respectively. and $\mathrm{F}$ represent the per unit (p.u.) speed and frequency respectively. The frequency and voltage of standalone induction generator are not limited and depend on generator parameter, speed, excitation capacitor and load.[12]

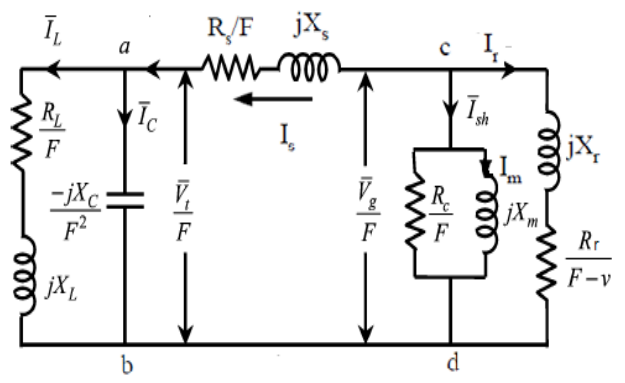

Fig. 1.1 equivalent circuitry of a 3 phase SEIG.

All parameters of generator $\mathrm{Rs}, \mathrm{Xs}, \mathrm{Rr}, \mathrm{Xr}$, excluding magnetizing reactance are supposed to be constant[13]. Magnetizing reactance $\mathrm{Xm}$ is considered to be varying in nature and dependent on magnetic saturation. Another flexible parameters in the circuitry are F, Xc , v, and load impedance. By using nodal admittance method the perphase Equivalent circuitry is solved[14]. The modified representation of circuitry is shown by Fig. 1 below.

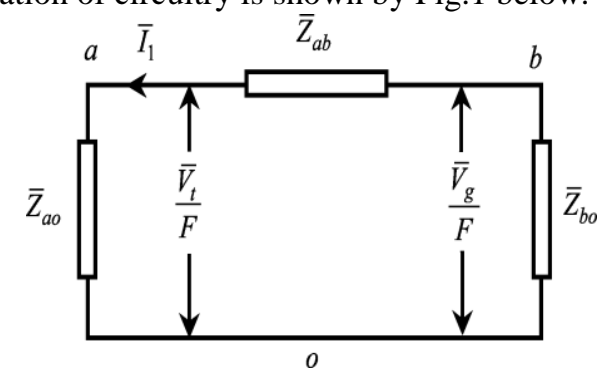

Fig. 1.2 modified representation of circuitry of Fig. 1.1

The air gap ratio of voltage to frequency $(\mathrm{Vg} / \mathrm{F})$ is dependent on the magnetizing reactance and magnetic flux. The interlink in between $\mathrm{Vg} / \mathrm{F}$ and magnetizing reactance can be developed from the data of synchronous speed testing. $\mathrm{Vg} / \mathrm{F}$ can be determined by the $3^{\text {rd }}$ order polynomial of minimum magnetising reactance the normal operating region.[15],[12].

$$
\frac{\mathrm{v}_{\mathrm{g}}}{\mathrm{F}}=\mathrm{k}_{1}+\mathrm{k}_{2} \mathrm{X}_{\mathrm{m}}+\mathrm{k}_{3} \mathrm{X}_{\mathrm{m}}{ }^{2}+\mathrm{k}_{4} \mathrm{X}_{\mathrm{m}}{ }^{3}(1)
$$

The least square method has applied to find the sharp curve of magnetization characteristic and the numerical based routine in MATLAB is used to find the coefficients of (1) and the coefficients of (1) are as

$$
\begin{aligned}
& \mathrm{k}_{1}=767.54, \\
& \mathrm{k}_{2}=-16.535, \\
& \mathrm{k}_{3}=-0.1843 \text { and } \mathrm{k}_{4}=-7.46 \times 10^{-4}
\end{aligned}
$$

Fig.1.3 represents magnetic characteristics of generator $\left(\mathrm{V}_{\mathrm{g}} / \mathrm{F}\right.$ vs $\left.\mathrm{X}_{\mathrm{m}}\right)$ which is obtained by solving equation 1 . Dotted line represents experimental result and solid line indicate the simulation results. It is clear from the figure that the ratio $\mathrm{V}_{\mathrm{g}} / \mathrm{F}$ decreases on increasing of magnetizing reactance $\mathrm{X}_{\mathrm{m}}$.

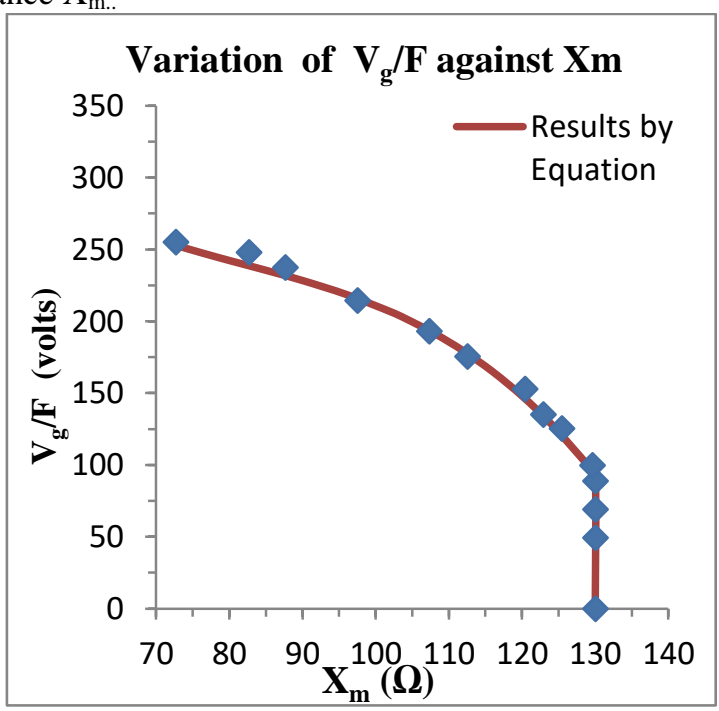

Fig: 1.3 Magnetization characteristic $\left(V_{g} / F\right.$ vs $\left.X_{m}\right)$ of the generator. 


\section{RESULTS AND CONCLUSION}

\subsection{Load Characteristics of SEIG}

Figure 1.5 shows load characteristics of SEIG (terminal voltage vs load power) at a synchronous speed for various values of excitation capacitors $(32 \mu \mathrm{F}$ and $36 \mu \mathrm{F})$. Points represent experimental result and solid lines indicate simulation results. From figure: 1.5 it is clear that when load impedance $Z_{L}$ is decreased (at no load) from infinity, output power $\mathrm{P}_{\mathrm{O}}$ increases and terminal $\mathrm{V}$ decreases until it reaches to maximum power point $\mathrm{P}_{\max }$, this is normal operation. If load impedance $\mathrm{Z}_{\mathrm{L}}$ decreases further, the output power and terminal voltage start decreasing until the critical voltage is reached, at this point loss of excitation occurs in SEIG and this is known as abnormal condition.

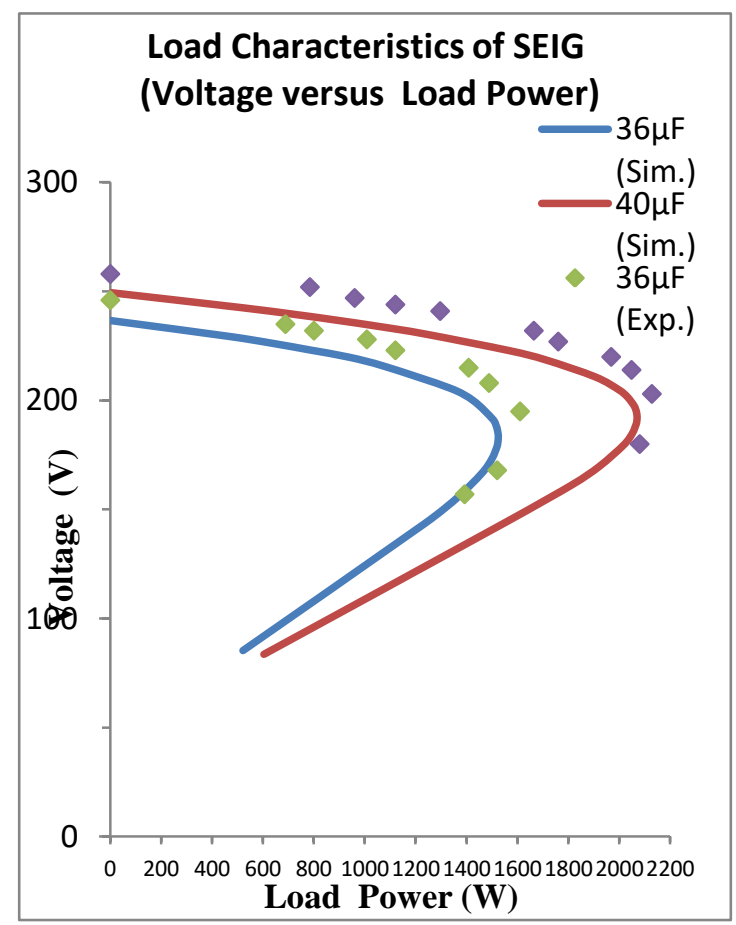

Fig.1.4 Terminalvoltagevs output power at $32 \mu \mathrm{F}$ and $36 \mu \mathrm{F}$ excited capacitors.

\subsection{CRITICAL CHARACTERISTICS OF SEIG}

For the purpose of self excitation, a minimum value of capacitance is required above which the voltage builds up. The value of capacitance depends on various parameters of machine such as its speed and power factor as well as its load impedance. Fig:1.4 shows the minimum value of capacitance required to build up the voltage in induction generator under different speed at no load. From figure it is clear that requirement of capacitance increases as the speed of machine decreases. If the speed of rotor decreases below a certain point (say critical point), then residual magnetism of the machine gets destroyed and can not be restored by further increase of capacitance.

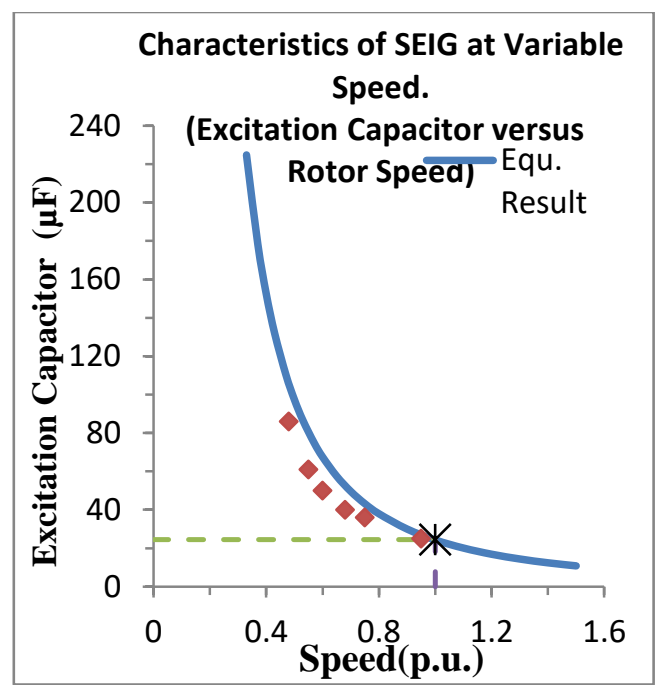

Fig: 1.5 Minimum capacitance required for an induction generator under different speed.

Here, the minimum value of capacitance evaluated is $25 \mu \mathrm{F}$. Experimental results are represented by dotted line and solid line indicates simulation results.

\subsection{CONSTANT TERMINAL VOLTAGE CHARACTERISTICS}

In order to achieved constant terminal voltage, the excitation capacitance must be varied. Fig:1.6 shows the variation of excitation capacitor against output power. Solid line represent simulation results and points indicate experimental results. As the value of load impedance $\mathrm{Z}_{\mathrm{L}}$ reduces, more value of capacitor are needed to maintain the terminal voltage constant. Figure shows the increasing value of excitation capacitance vs load power at constant terminal voltage. Due to the constant terminal voltage, the load current $I_{L}$ increases linearly with increase of output power $\mathrm{P}_{\mathrm{O}}$ which is shown by Fig: 1.7 .

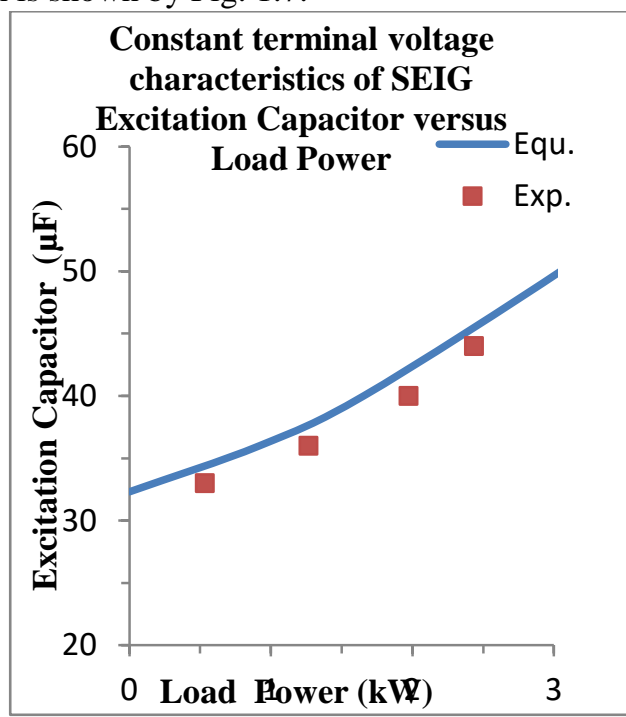

Fig. 1.6 Excitation capacitor versus output power of a constant-terminal-voltage operation 


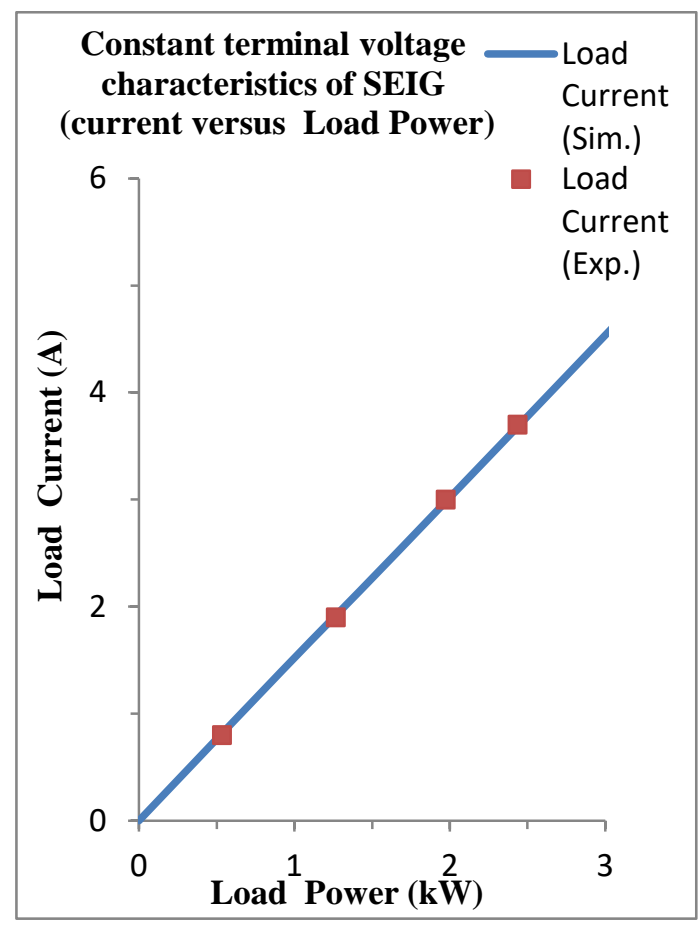

Fig. 1.7 Load current versus output power of a constant-terminal-voltage operation.

The experimental result of load current vs load power is indicated by dotted line and simulation results is represented by solid lines.

\subsection{CONCLUSION}

SEIG is very much suitable and economical in isolated areas for the purpose of generating electricity because it requires less maintenance, reliable and robust in nature and also capable of generating power at varying speed. SEIG is not available in market so an induction motor is used as SEIG with specific value capacitor. But due to small hysteresis area its residual magnetism is very low and can be lost rapidly if there is too much demand of load current. This rapid lost of residual magnetism requires restoration again and again, which may increase the cost of SEIG. Therefore, if a critical point is known above which residual magnetism of rotor gets destroyed, then a relay can be applied to the machine so that it could send a tripping signal to the machine just before draining of residual magnetism. By doing so, there will be no need for restoration of residual magnetism and this makes the SEIG economical.

The experiment has been performed in the laboratory with three-phase, $1.5-\mathrm{kW}, 415-\mathrm{V}, 1440-\mathrm{rpm}$, four-pole, delta connected generalized machine operating as SEIG driven by $2 \mathrm{hp}, 415 \mathrm{v} 1500 \mathrm{rpm}$ shunt connected dc motor. In this experiment the minimum shunt capacitance is found to be $C_{s h}=25 \mu \mathrm{F}$ at which the excitation starts to built up in SEIG.

\section{REFERENCES}

1. N. L. Panwar, S. C. Kaushik, and S. Kothari, "Role of renewable energy sources in environmental protection: A review," Renewable and Sustainable Energy Reviews. 2011.

2. R. Lauge-Kristensen, "Renewable energy," in Sustainable Practices in the Built Environment, Second Edition, 2008.

3. T. Ahmed, E. Hiraki, M. Nakaoka, and O. Noro, "Threephase self-excited induction generator driven by variable- speed prime mover for clean renewable energy utilizations and its terminal voltage regulation characteristics by static VAr compensator," 2004.

4. R. C. Bansal, "Three-phase self-excited induction generators: An overview," IEEE Transactions on Energy Conversion. 2005.

5. Analysis of Electric Machinery," IEEE Power Eng. Rev. 1995.

6. G. K. Singh, "Self-excited induction generator research A survey," Electr. Power Syst. Res., 2004.

7. T. F. Chan, "Capacitance requirements of self-excited induction generators," IEEE Trans. Energy Convers., 1993.

8. S. S. Murthy, O. P. Malik, and A. K. Tandon, "Analysis of self-excited induction generators," IEE Proc. C Gener. Transm. Distrib., 2010.

9. F. Abdoune, D. Aouzellag, and K. Ghedamsi, "Terminal voltage build-up and control of a DFIG based stand-alone wind energy conversion system," Renew. Energy, 2016.

10. S. P. Singh, B. Singh, and M. P. Jain, "Comparative study on the performance of a commercially designed induction generator with induction motors operating as self excited induction generators," IEE Proc. C Gener. Transm. Distrib., 2010.

11. A. Abbou, M. Barara, A. Ouchatti, M. Akherraz, and H. Mahmoudi, "Capacitance required analysis for selfexcited induction generateur," J. Theor. Appl. Inf. Technol., 2013.

12. A. L. Alolah and M. A. Alkanhal, "Optimization-based steady state analysis of three phase self-excited induction generator," IEEE Trans. Energy Convers., 2000.

13. D. Joshi, K. S. Sandhu, and M. K. Soni, "Constant voltage constant frequency operation for a self-excited induction generator," IEEE Trans. Energy Convers., 2006.

14. S. Rajakaruna and R. Bonert, "Technique for the steadystate analysis of a self-excited induction generator with variable speed," IEEE Trans. Energy Convers., 1993.

15. S. S. Murthy, B. Singh, and V. Sandeep, "Design-based computational procedure for performance prediction and analysis of single-phase self-excited induction generator," IET Electr. Power Appl., 2013. 